not have taken place many generations ago. On this account it is not possible to say whether the tree from which the germinated acorns were taken was the imgeneration of its progeny.

in which the parents show large number of dissimilar characters the first generation rarely offers the spectacle of pure dominance of the characters ness of those from the other parent. It is only whe the parents differ by a point or two that such total dominance is seen and the first generation or the immediate product of the cross resembles one parent or the other, and its progeny split in the next genera. tion. In cases such as that under discussion, an which is also illustrated by the walnuts, the first gen eration shows a mixed dominance as well as a possible fractionization of some meristic qualities, so that the hybrid appears as an intermediate between the two may be variously estimated. In the second generation the movements of the recessives coupled with the range of fluctuating variability should give a wide diversity of types, varying in number with the number of differentiating points of the parents of the cross which may include both parents, the type of the firs generation, and

By reason of the number of dissimilar characters involved in such a cross the probability of deriving an individual composed entirely of recessive characters or of the particular combination characteristic of either ancestor is very small. A progeny of hundreds of thousands of species would be necessary to furnish combinations.

While it may not be said that any of the plantlets of the progeny under observation are reconstituted ancestral forms, yet some of the individuals include so many of the qualities of the red oak and willow oak that the evidence is overwhelmingly in favor of the attributed to the hybridization of these two forms. Taking this conclusion as established, it may then be said that the name $Q$. heterophylla is at present ap plied to a medley of oak trees which possibly includes the first generation of a cross between Q. rubra and $Q$. Phellos, secondary hybrids with either parent, as well as successive generations in which various com binations of ancestral qualities may appear.

Another aspect of the parental form of the above hybrid and the progeny remains to be mentioned. A collector covering the field occupied by the hybrid in which the parental forms come into contact, who gath would have data upon which mistaken conclusions a to intergradation of species by fluctuating variability might be made. This leads to the suggestion that any supposed intergradation of two species of seed plants izations before any final estimate is reached in the matter.

Furthermore, it is to be seen that while in all rea sonable probability opportunity for hybridization be tween these two oaks has been present for a period of unknown but undoubted great length, yet it has not resulted in anything in the way of occurrence or distribution suggestive of the disappearance of either parental form. The probably greater frequency of intra-specific fertilization over hybridization would secure this result. Then again it is to be seen that of the individuals, there would be the probable re constitution of the ancestral forms among the progenies.

Quercus Rudkini has long been reputed to be hybrid between $Q$. Phellos and $Q$. Marylandica, and a visit was made to the group of trees from which the species was. originally described by Dr. Britton, in company with him and other botanists in October 1905. These trees stand near Key others have been found on Staten Island and also to some distance to the southwestward in New Jersey. The mere facts of distributional relations together with the anatomical features offered by the bark and leaves led to the description of these trees as being of a hybrid origin facts only are taken into account, it seems quite a plausible to regard this tree as a hybrid of $Q$. heterophylla. The leaves taken-from the included trees showed a range of forms that included the type of $Q$ Phellos, but did not go wide enough to show duplicate by Dr. Britton (Bull. Torr. Bot. Club, 9:13:1882). The acorns likewise ranged from the form near that of $Q$. Phellos toward Q. Marylandica, but included none that might be mistaken for the latter. The bark of the various individuals on the other hand seemed most like $Q$. Marylandica, although much variation was apparent.

During the visit of 1905 acorns were found on trees germination the types only, and material capable these were at the end of the first year's growth, which and ended in September, it was seen that the progenies of the three parents, selected for their dissimilarity, were fairly identical; and while a wide rimilarity, were fairly identical; and while a wide range of variability was found, yet this range did no
exceed the limits of similar fluctuations offered by other species of oaks which are known to be unifiel hereditary strains.
The leaves of these seedlings did not include forms which might be mistaken for those of either parent It is to be seen therefore that the cultural observa tions revealed no evidence to show that Rudkin's oak is of hybrid origin, although it did not disprove it Synthetic tests, which take much time, and detailed anatomical examinations are yet to be resorted to. It is quite possible that the group of trees examined may represent some segregation of the ancestral qualities and not the full range of combinations discovered in $Q$. heterophylla. Meanwhile this oak, which is thus constant in successive generations within the limits of its variability, must be regarded as a species in accordance with current taxonomic practice, unt

some positive evidence to the contrary is obtained.

The principles illustrated by the foregoing facts may briefly summarized as follows:

It is obvious that the facts of geographical distribu ion may be relied upon to furnish conclusive evidence as to the origin of a species or a hereditary quality ty under very exceptional conditions in which othe possibilities are excluded, and then only in a circum fact that species not in contact may not hybridize, bu the converse is true only when otherwise proven.

So far as the plants of suspected hybrid origin from parents suggested by distributional relations are concerned, the methods of investigation available are two which may separately secure affirmative evidence of conclusive value, while the third may bring no more than confirmations and suggestions.

Attempts at synthesization, if successful, yield de pendable conclusions as to the composition of a hybrid, yet a failure to secure a form by synthesis may be hybridization of the forms concerned, by the different results of reciprocal crossing and the difference in physiological attributes of elementary species included under one name. Furthermore, the natural form the ancestry of which is under search may have been a derived hybrid which became fixed in the $n$th generation by a fortuitous combination of dominant char acters. To secure a similar result in an experim test might be beyond the range of probability. In an anatomical examination such a combination of dominant and recessive characters with fuctuation make the results of but little value until confirmed by data derived from other sources, before their ful value may be known.

A study of a fixed hybrid by cultural tests of it progeny will reveal nothing as to its origin, and synthesization and anatomic examinations are the only recourse. On the other hand, if the progeny exhibits alternative inheritance, its components may show un mistakably the nature of the original cross.

The last-named method demonstrates beyond reasonable doubt that Bartram's oak is a hybrid derivative of the willow oak and red oak, the progeny being probably characterized by alternative inheritance of some of the qualities, and fractionization of others in
stead of being a unified hereditary strain. Some o the plantlets included in a progeny of 55 individuals were apparent re-constitutions of the ancestral types as observed at the close of the

Rudkin's oak on the contrary yields no evidence in cultures of its progeny on which a defensible conclusion as to its origin may be based. The individual variability of the trees included under this name is very great, and some of these approach the willow oak in leaf form, and some of the characters of the acorns. The study of over a hundred plantlets showed a wide and practically identical range of variation. Alternative inheritance could not be traced. The individuals known under the name of $Q$. Rudkini produce a large proportion of imperfect acorns, but beyond this no facts suggestive of hybrid origin can be found, except the anatomical resemblances noted.

A list of the natural plant hybrids of North Americ was prepared by Mr. David George for presentation at the International Hybrid Conference in New York in 1902 but was not published. In this list it was noted that 117 natural hybrids had been reported as occurring in the indigenous flora of North America, in mosses. The some instances among the ferns an disposal by the director of the New York Botanica Garden, a revision of the list has been made, some of the original references being omitted and a few added. No attempt has been made to make it actually complete, the sole purpose being to suggest material for
extended observations similar to those described in this pape

The reported hybrids are distributed among the natural families as follows:

Naidaceæ. Two cases in Potamogeton.

Juncaceæ. One hybrid, between Juncus effusus and
J J. Pacificus.

Liliacex One hybrid between Calochortus Ben tham 2 and B. albus.

De hybrid between Habenaria lacera and H. psycodes.

Juglandaceæ. Three hybrids of Hicoria pecan with H. minima, H. alba, and $H$. laciniosa.

One hybrid between .Juglans nigra and J. cinerea. Salicaceæ. About twenty supposed hybrids of Salix

Two hybrids of Betula are also reported between $B$. pumila and $B$. lenta and between $B$. populifolia and Fagaceæ. Thirty-five oak hybrids have been report

ed, but one of these, Q. Rudkini, has been tested as Ranunce above with negative results. A. ruora. Clematis viornoides is reported to be of hybrid nature.

Cruciferæ. Roripa palustris is supposed to torm natural hybrids with $R$. obtusa and $R$. sinuata.

Pomaceæ. Malus Soulardi is taken to be a cross between $M$. coronarius and $M$. Malmus by some work-

Rosaceæ. Geum strictum and G. Canadense are supposed to form a hybrid.

Papilionaceæ. A hybrid between Baptisia australis and $B$. bracteata is reported.

R. glabra.

Rhamnaceæ, Ceanothus Lobbianas is taken to be hybrid between $C$. thyrsiforus and $C$. dentatus. It is also supposed that $C$. thyrsifor
papillosus and $C$. sorediatus.

Violaceæ. A large number of hybrids of Viola have been reported.

Onagraceæ. Oenothera biennis and O. Oakesiana ing of several types.

Cactaceæ. A hybrid .is supposed to be tormed be tween two species of Opuntia.

Cornus Baileya has been taken to be a hybrid between $C$. asperifolia and $C$. stolonifera. Verbenacex. The evidence seems strong that Ver hastata, V. bracteosa and V. urticufolua, V. bracteosa and $V$. stricta, V. stricta and $V$. hastata, V. stricta and folia and V. stricta, and V. angustifolia and V. brac-

Acanthaceæ, Ruellia ciliosa parvifora has been upposed to be the result of a cross between $\boldsymbol{R}$. ciliosa and $R$. strepens.

Lobeliaceæ. Lobelia syphilitica is supposed to hybridize with $L$. cardinalis.

Cichoriaceæ. Prenanthes Mainensis is taken to be cross between Nabalus racemosus and N. trifoliatus. Solidago, Aster, Bidens and Helenium.

The genera noted above are supposed to offer about two hundred hybrids; and as the observations have been made principally with the flora of eastern North America in a region which probably does not furnish more than twenty thousand species, it is to be seen tha the questions involved affect about one per cent of the
lora. Probably not more than half of the instances included in the above list could be confirmed by actual tests, but on the other hand it is probable that a closer examination would reveal an equal number of actual occurrences.

Some of the constituents of the native flora are known to be constant unitypic hybrids, and hence have hybridization most widely different from this is illus trated by Bartram's oak, and between these two diverse modes of action may be found. In gaining in which the qualities of separate unified strains of plants are alternative, or are interlocked, or fractionized in hybridizations, a vantage ground will be gained for the consideration of all questions in gen tions of such characters.-Botanical Gazette.

\title{
THE FEAR OF OPEN AND CLOSED SPACES.
} By Charles Mercier, M.D.

AgoraphoBia, or fear of open spaces, is not nearly as common a malady as its antithesis, claustrophobia. Both are curious, and somewhat anomalous, states of
mind, in which an aversion, which is known and admitted by the subject of it to be irrational and absurd, nevertheless dominates conduct, prompts the execution of irrational acts, and

If I had to speculate on the origin of these curious and spurious instincts, for such they may be termed, I should assign them to the revival of instincts which existed in full force, and had great biological value, Ir our remote ancestry, but which in most of us hav in habit, this habit was their salvation from extinction. Feeble in body, destitute of weapons and of defensive from they could climb foes lay in the agility with which with which they could leap from bough to bough and from tree to tree. Whenever they descended to the ground, they were in danger. It is on the ground that the greater carnivora pursue their prey; and, adapted as our ancestors were to arboreal life, their progress on open ground was undoubtedly less rapid than among the tree tops, and most probably less rapid than that of their principal foes. Among the tree tops they were secure. There, no enemy could vie with them in they were at a disadvantage. On the flat, they had no chance against the spring of the panther or the speed and wind of the wolf; but once let them attain che security of the forest, and they could grin an 
of their existence, our ancestors had a very strong in-
stinctive aversion to any extended excursion from their place of security and refuge. Near to trees, they were in safety; far from trees, they were in continual dan. ger, and therefore in continual uneasiness. In such and sense of

This is the state of mind which, as it seems to me, is reproduced in similar circumstances in agoraphobia. The craving of the subject of this malady is to be near, not trees necessarily, it is true, but near to some tall vertical structure. Away from such a structure, he has just the feeling of dread, of impending danger, happen, that a man would have who was walking through a jungle infested by tigers, or that a child has when alone in the dark. And this is just such a feeling as we may suppose our arboreal ancestors had when they were out of reach of their natural habitat. from one side of a court to the other by not only going round by the wall, and touching it all the way, but squeezing herself up against it, and clutching at the bare surface. Sufferers from this malady cannot cross an open space. They cannot venture more than uneasiness in a colonnade, open all around them though it be. Their reason tells them that their dread is groundless, but reason is powerless against instinct and an imperious instinct shouts danger in their ears. to repposite malady-claustrophobia-seems to me rence in our racial history. When arboreal habits at length began to be abandoned, and our anthropoid ancestors began to shelter themselves in hollow trees, in caves, and holes in the ground, there must of ten primitive a confict between the immeasurably old, the modern innovation of taking shelter from the weather. The sense of confinement must have been very irksome. We may be sure that there was no sud-
den revolution in the mode of life. The new habit was adopted very gradually. Only in some very violent storm would the first indwellers creep into a hole for shelter, and they would soon find their circumscribed quarters intolerable, and brave the elements as soon as the weather began to moderate. Perhaps the new instinct was first implanted in the young, by the parents
bestowing their tender offspring in holes during their own absence or when cold and rain became severe. is not easy to teach an old dog new tricks; but a young wild rabbit or squirrel, taken at a very early age from the nest, never acquires the untamable wildness that is so conspicuous a feature in the character of the old. In any case, the habit of taking shelter in more or less closed spaces was a habit of slow and backsliding. We can almost hear the jeers and scoff of the stout old Tory anthropoids at the effeminacy of their degenerate juniors, who should seek a shelter that their forefathers would have scorned. The habit has not yet been fully acquired by all our race, for we status to whom the shelter of a roof is abhorrent, and who prefer, in the worst of weather, to lie out under a hedgeside rather than submit to the restraint of roof and walls.

It is to the imperfect acquisition of this later in stinct of seeking shelter in confined spaces-or rather earlier instinct of craving for the men sky, and irksomeness of confinement-that the malady of claustrophobia seems to me to be due. In the subject of this malady is revived in its original strength that craving for open sky and open air, for possibility of movement in every direction, which were ingrained in our an cestors by their free arboreal lives; and which were overcome with such difficulty when first they descended to inhabit terra firma. Like the sufferer from agoraences the who suffers from claustrophobia experiobsolete revival of an ancestral instinct that has been more recently than generations, but that has been lost it existed down to a later date since it has been more recently lost, it is more easily revived; and this is the reason, I think, that claustrophobia is so much less rare than agoraphobia.-London Lancet.

ATMOSPHERIC DUST

THE importance of dust in the economy of the atmosphere is not to be underrated, but neither should it be overestimated. If dust is present in the air, the light reflected therefrom has various tints of gray or of dust, but if no dust is present, light may be reflected of dust, but if no dust is present, light may be reflected
from any minute particles of water or ice that happen to be present, and these are not generally called dust. to be present, and these are not generally called dust. by gathering about particles of dust as nuclei, but they can also form such drops without dust as nuclei, and can also form such drops without dust as nuclei, and
must frequently do so. However, if neither dust nor must frequently do so. However, if neither dust nor
water were present in the atmosphere, we should still water were present in the atmosphere, we should still
have our ordinary blue sky light, and some sunset sky colors. The deep blue of the sky is due almost entirely to the selective dispersion of the various waves or rays of light that come from the sun, by the action of the molecules of the constituent gases of the atmosphere. given wave length depends upon the relative dimen given wave length depends upon the relative dimen-
sions of the wave and the molecule. The exact relation has been carefully worked out by Lord Rayleigh, whose formulæ explain not only the blue color of the sky, but cles and ordinary water or ice that light. Dust partiso large that they reflect ail rays of light, with a slight possible predominance of the red rays or long waves; consequently the hazy whites and grays of mer may be attributed to dust and vapor, which in fact obscure the deep blue sky light.

Aqueous vapor in its finest condition, when it begins to condense without the help of dust nuclei, has the power of selectively reflecting the longer or bright blue as distinguished from the shorter dark blue of the pure upper sky; the resulting bluish haze may often be look at a distant landscape, and especially in the pure air of oceanic islands. The blue haze off the west coast in the laboratory proverbial. This haze was first studied in the laboratory by Tyndall, when he produced it uninside the vacuum tube.

The beautiful colored sunsets observed in connection with the eruption of Krakota, and especially the brilliant colors brought out by Prof. Carl Barus, of Brown University, in his study of cloudy condensation, are not due to dust nor to the selective reflection by fine particles, but are examples of a very different process, i.e., the colors of thin plates, or what Newton called the colors of thin films. The central portion of each the colors of thin films. The central portion of each
little sphere of water transmits a minute beam of sun. little sphere of water transmits a minute beam of sun-
light which has been reflected to and fro within the sphere, and its waves have interfered with each other. sphere, and its waves have interfered with each other.
Some have been reinforced and others have been anSome have been reinforced and others have been an-
nulled. The former give the beam that is seen by the nulled. The former give the beam that is seen by the
observer, and its color depends on the diameter of the observer, and its color depends on the diamete
sphere or the thickness of the film of water.

In general, therefore, our beautiful atmospheric colors are not altogether due to dust.-Monthly Weather

\section{TRADE NOTES AND FORMULA.}

Zwieback Extract.- It is stated that these extracts, which are said to be of Dutch origin, contain a large quanity of soap. This admixture of soap is probably
intended to produce the fiaky, frothy dough so greatly intended to produce the fiaky, frothy dough so greatly valued in biscuits and zwieback, and these extracts
are expressly recommended for use in the baking of are expressly

Beated Circular-Saw Blades.-Circular-saw blades that have run hot should not, as the Allgemeine Tischlerzeitung observes, be cooled with cold water, as they are liable to warp or become distorted. The cooling must be gradual; the saws should be allowed ly to stop of their own accord. Only in extreme cases may an attempt be made to accelerate the cooling proPractical Directions for Making Ink Eradicators.Dip a thick piece of white absorbent (blotting) paper
into a solution of 100 parts of oxalic acid in 400 part of alcohol; keep the paper in the liquid until it is of alcohol; keep the paper in the liquid until it is
thoroughly saturated, and then dry by suspending in the air. Aniline ink spots cannot be removed by this the air. Aniline ink spots cannot be removed by this
paper. Since, however, ink containing iron is much more commonly used than aniline ink, this paper wilt be found indispensable for the office when once introduced.-Neueste. Erf. u. Erfahr.

To Make Varnish for Roofs.-The following recipe for preparing varnish for roofs is given by the Erste österreichische Dachdeckerzeitung: 700 parts by
weight of distilled coal-tar are heated in a boiler and 70 parts degras added when the tar is still liquid. This should be constantly stirred, and a mixture of 175 parts by weight of washed brown coal ashes, 20 parts of flowers of sulphur, and 35 parts of alum gradually added. The varnish is applied hot, like other varnishes. Sanding the roof does not appear necessary, as the varnish dries quickly and will
drip off.-Neueste Erfindungen und Erfahrungen.

A Paste Which Will Adhere to Tin.-According to a communication to the Apothekerzeitung, Lemoine pre pares a paste which will adhere to tin by mixing 2 water, vigorously stirring the liquid and allowing it to settle. A mass is made, at the same time, of
parts of cold water, 6 parts of rye flour, and 1 part of dextrine and added to the tragacanth solution. This liquid is then mixed with 24 parts of boiling water, stirring constantly, and further with 1 part of glycerine and 1 part of salicylic acid; the whole mass fore found that ordinary starch paste, with the addition of some glycerine, also possesses the property of adhering to tin, and this simpler compound will pro
suffice for most purposes.-Neueste Erf. u. Erf.

To Clean Marble Slabs.-Though we have on a pre vious occasion given directions for cleaning marble, on this subject communicated to the Pharmazeutische Post by the engineer and chemist, A. Gawalowski. Grease spots may be covered to the thickness of the zine, and the dried magnesia crust removed in one to two hours. Fxtract spots can be removed - in the same hours. Extract spots can be removed - in the same
manner by a paste composed of talc, fibrous gypsum manner by a paste composed of talc, fibrous gypsum, acid with alcohol and diluted. Or a bleaching paste is made from barium peroxide and dilute sulphuric acid, mixing these ingredients at a very low temperature and avoiding acid reaction, $i$. e., excess of sul-
phuric acid, and applying as above. According to
Gawalowsli, calcium peroxide, magnesium peroxide, or is afterward polished with putty powder and paraffine

\section{ENGINEERING NOTES.} The treatment of unsuitable feed water for locomo-
tive use has long been recognized as a necessity, and crude methods with such practical means and facilities as have been available, have been practised for many the With the increased capacity of locomotives, the amount of water evaporated and the supply of
water required has resulted in the necessity for im. proved apparatus and storage capacity to provide for such chemical treatment, which, combined with mechanical means, will produce the best results.

An iron smelting plant having steam turbines and gas fired boilers in the power station may at present consume all of its available gas in the blast furnace rolling mills is to be added, or if other industries are attracted to settle in the neighborhood, or if some community or city would build up in the immediate vicinity of the plant to whom it might be desirable to
sell power at a profit, then the works management sell power at a profit, then the works management
would be confronted by the necessity of either buying good steam coal, or else of consigning steam turbines and boilers to the scrap heap and of replacing them by gas engines able to generate the required additional
energy from the available gases or other waste at no additional cost.

The fact that the compound can be replaced by the simple locomotive, with increase of power and low pressure in the boiler, is an advantage. of superheated steam, even if no economy in fuel is obtained. As superheated steam applied to locomotives gives a higher thermo-dynamic efficiency than that realized from compound locomotives using saturated steam, it will enable the possibility of obtaining the advantages of compounding, without the introduction of the objec-
tionable features. The possibility for increasing the capacity and economy of present locomotives by superheating is of even greater importance, as boilers which may be deficient in design or capacity can be much improved in effectiveness, and superheaters can be ap-
plied without altering the general design or construcplied without altering the general
tion of the boiler or mechanism.

The conditions which will beset the engineer of the now know. The importance of a strong foundation in now know. The importance of a strong foundation in
scientific principles cannot be overestimated, for scien. tific principles are only the laws of nature. These principles cannot be learned readily after a man has principles cannot be learned readily after a man has
begun his life work. His whole energy will then be devoted to applying these principles correctly, not in devoted to applying these principles correctly, not in
acquiring them laboriously. It will be a prime necessity for the technical college of the future to lay these foundations broad and deep. It will be regarded as a weakness for a college to teach its students only the knacks of the profession, only just enough to be an ordinary draftsman, a tolerable surveyor, or firstclass linesman.

It sounds a strange thing to say that good drainage is in some degree synonymous with good dividend. cost and the exercise of skill in properly dealing with water ultimately saves much money in maintenance.
Most of the ills the civil engineer is heir to are atMost of the ills the civil engineer is heir to are at-
tributable to the effects of water; and from the point tributable to the effects of water; and from the point
of view of the economies of the maintenance of works, of view of the economies of the maintenance of works,
water may be described as the greatest of the forces of nature with which the civil engineer has to contend. The debit of maintenance and revenue account in respect of remedial work necessitated by the ac-
tion of water is enormous; young engineers should mark specially, and inwardly digest the saying at tributed to a well-known Scottish contractor of the recent past: "Ye canna cheet watter." Never was there a saying more true. It is not so much the im. petuous flood and the flowing tide that one has to
guard against, and never forget, in the design of guard against, and never forget, in the design of
works from the point of view of maintenance, but rather the terribly insidious and stealthy action of water, which never stops, and which inevitably re
sults in decay as silent and as certain as the grave.

An invention which will prove of widespread utility to the textile industry has recently been devised con. jointly by three English engineers for tow-carding upon an extensive scale. The machine is essentially of the labor-saving class, it being possible to accomplish as much therewith as has hitherto required fifteen hands. Tow, the by-product of flax, has here-
tofore always necessitated hand-feeding into the carding machines-one hand to each card. With this maing machines-one hand to each card. With this ma-
chine, however, this requisition is dispensed with. chine, however, this requisition is dispensed with.
The tow to be carded is sorted and weighed, and then discharged through a shoot onto the table of the machine below. 'The operator here controls the feeding of the tow into the machine. The material is drawn
into the lapper, as it is called, by a sheet and shell into the lapper, as it is called, by a sheet and shell
feed roller. It is then struck sharply by a rapidly. feed roller. It is then struck sharply by a rapidly.
revolving cylinder, and discharged on to a traveling revolving cylinder, and discharged on to a traveling
lattice sheet, which carries . it forward to a set of pressing rollers. It is here formed into a large sliver, in diameter. When finished on the core the laps are in diameter. When finished on the core the laps are
doffed by hand, the full lap being withdrawn and the new core inserted without stopping the machine. The lap, which is 56 pounds in weight, is placed on a carrer and transported by an elevated railroad to the
carding machlnes and deposited where required. This 